\title{
Utilizing Benign Oxidants for Selective Aerobic Oxidations using Heterogenized Platinum Nanoparticle Catalysts
}

\author{
Christopher S. Hinde, ${ }^{[a]}$ Arran M. Gill, ${ }^{[a]}$ Peter P. Wells, ${ }^{[b, c]}$ T. S. Andy Hor, ${ }^{[\mathrm{d}, \mathrm{e}]}$ and Robert Raja ${ }^{*[a]}$
}

\begin{abstract}
By using platinum nanoparticle catalysts that are generated in situ by extrusion from a porous coppeB5 chlorophosphate framework, the role of oxidants in the selective oxidation of benzyl alcohol to benzaldehyde was evaluated, with a

5 view to establishing structure-property relationships. With a detailed study of the kinetic properties of the oxidation reaction, it has been determined that the aerobic oxidation pathways progress with loweno levels of product selectivity and higher activation energies (72.4 $\mathrm{kJ} / \mathrm{mol}$ ) than the peroxide-based ones $(23.6 \mathrm{~kJ} / \mathrm{mol})$; affording

10 valuable insights in the design of solid catalysts for selective oxidation reactions. Furthermore, through the use of X-ray absorption spectroscopy, the effect of calcination temperature on thet5 degree of extrusion and its influence on nanoparticle formation have been evaluated, leading to the establishment of structure-activity

15 correlations between the observed activation energies and the proportion of nanoparticle species generated.
\end{abstract}

Oxidation reactions are ubiquitous in the pharmaceutical and fine-chemical industries, and are fundamentally important to introducing oxygen rich functional groups to organic molecules $_{55}$

20 For example, aldehyde and ester containing molecules are heavily employed as flavouring and fragrance agents due to their volatility and distinctly aromatic nature that are often pleasing to smell and taste. ${ }^{[1]}$ Benzaldehyde is a key component for most almond-based flavourings, although it finds other uses

25 as precursors for plastic additives and as a pharmaceutical intermediate toward antibiotic drugs such as chloramphenicol and ampicillin, as well as stimulants like ephedrine. ${ }^{[2]}$ Industrially, it is synthesized by the hydrolysis of benzal chloride, however the dehydrogenative oxidation of benzyl alcohol is a viable 30 chloride free and environmentally benign alternative. ${ }^{[2]}$

Traditionally, industrial oxidation reactions are based on the use of stoichiometric quantities of inorganic metal-based oxidizing agents such as $\mathrm{MnO}_{2}$ or $\mathrm{CrO}_{3}$, or harsh mineral acids
[a] C. S. Hinde, A. M. Gill and Dr. R. Raja
University of Southampton
Southampton, SO17 1BJ, UK.
E-mail: R.Raja@soton.ac.uk
[b] Dr. P.P. Wells
UK Catalysis Hub
Oxon, OX11 OFA, UK.
[c] University College London
London, WC1H 0AJ, UK.
[d] Prof. T. S. A. Hor
Institute of Materials Science and Engineering (IMRE), Agency for
Science, Technology \& Research (A*STAR), 3 Research Link, Singapore, 117602.
[e] Department of Chemistry, National University of Singapore, 3
Science Drive 3,
Singapore, 117543

Supporting information for this article is given via a link at the end of the document. like $\mathrm{H}_{2} \mathrm{SO}_{4}$ and $\mathrm{HNO}_{3}$, which result in hazardous, corrosive and toxic operating conditions as well as leading to the generation of large quantities of polluting waste by-products. ${ }^{[3]}$ Due to the heightened socio-economic demand for the chemical and related industries to reduce their negative impact on the environment, there is a significant drive to find alternative economic and sustainable oxidation reagents and synthetic protocols. ${ }^{[3]}$ The abundance of molecular oxygen, its high atomeconomy in oxidation reactions, low costs and mild reaction conditions make it an appealing candidate as an oxidant, ${ }^{[4]}$ although high-pressure and relatively high reaction temperatures are often required, owing to the gaseous nature of the reaction. Similarly, simple peroxides such as $\mathrm{H}_{2} \mathrm{O}_{2}$ and tert-butyl hydroperoxide (TBHP), are often considered as alternative green oxidants. ${ }^{[4]}$ Although, this often leads to the generation of larger quantities of by-products in comparison with molecular

50 oxygen, they are slightly more reactive due to the lower bond dissociation energy (BDE) of the single $\mathrm{O}-\mathrm{O}$ bond $(49.7 \mathrm{kcal} / \mathrm{mol}$ for $\mathrm{H}_{2} \mathrm{O}_{2}$ and $45.0 \mathrm{kcal} / \mathrm{mol}$ for TBHP) ${ }^{[5]}$ compared with $\mathrm{O}=\mathrm{O}$ $(118 \mathrm{kcal} / \mathrm{mol}),{ }^{[6]}$ with the added potential to operate under comparatively mild conditions. Nonetheless, suitable catalysts are often still required to activate the oxidants in order to achieve respectable activity and selectivity within reasonable reaction conditions.

In recent years, supported noble metal nanoparticle (NP) catalysts have shown great promise in the activation of both molecular oxygen ${ }^{[7]}$ and simple peroxides ${ }^{[8]}$ to achieve selective oxidation of alcohols, and more recently, activation of $\mathrm{C}-\mathrm{H}$ bonds in hydrocarbon substrates such as toluene. ${ }^{[8 c, 9]}$ We recently reported a new method for the synthesis of highly active, uniform and site-isolated metal NPs in situ, by extrusion of chlorometallate precursor anions from the 1D channels of a porous copper chlorophosphate (CuClP) framework, for the activation of $\mathrm{O}_{2}$ and base-free oxidation of alcohols. ${ }^{[10]}$ It was demonstrated that calcination of the as-synthesised materials in air could generate fractions of supported, active NP catalysts for 70 the aerobic oxidations, with the $\mathrm{Pt} / \mathrm{CuClP}$ showing the best activity and selectivity. A significant challenge in the development of sustainable oxidation catalysts relies on a detailed understanding of the nature of the active sites at a molecular level, which requires a multidisciplinary design-

75 application approach, drawing on strengths of materials chemistry and spectroscopic characterization. By gaining indepth knowledge of the local structural environment of the active centres within catalytic nanostructures (through x-ray absorption spectroscopy), precise structure-property correlations can be

80 established, with a view to adopting a more generalized approach for the predictive design of single-site heterogeneous catalysts in industrially-significant, sustainable oxidation reactions.

In this study, we evaluate the propensity of $\mathrm{Pt} / \mathrm{CuCIP}$ catalysts toward the activation of $\mathrm{O}_{2}$ and TBHP for the selective 
oxidation of benzyl alcohol to benzaldehyde in batch conditions. Through detailed kinetic studies, activation energies are calculated to compare the ability of the catalysts to activate both oxidants, with the selectivity profiles critically evaluated to

5 establish the merits of each process. In addition, the effect oBO calcination temperature on the activation of the catalyst will be studied, to investigate its influence on the resulting catalytic properties, in order to facilitate structure-property relationships.

(a)

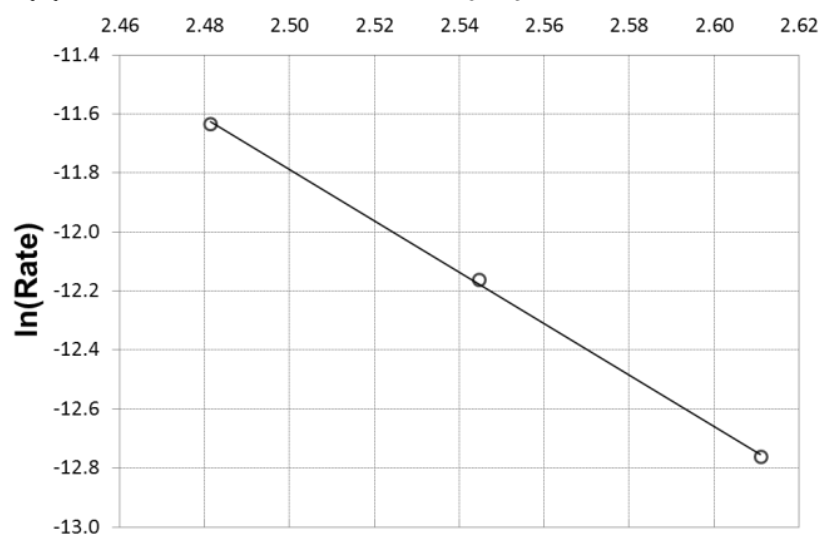

(b)

$1 / \mathrm{T} \times 10^{-3}\left(\mathrm{~K}^{-1}\right)$
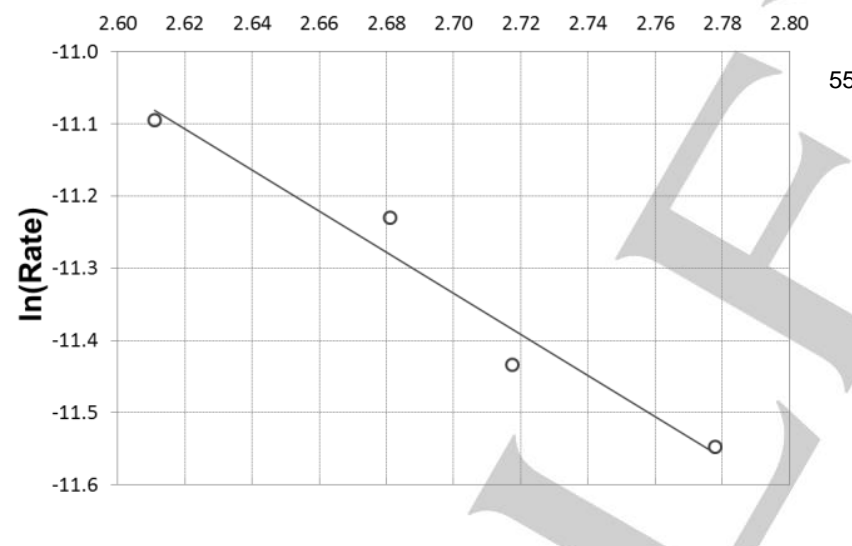

Figure 1. Arrhenius plots for the (a) aerobic and (b) TBHP oxidations of benzyl alcohol with calcined $\left(500{ }^{\circ} \mathrm{C}, 2 \mathrm{~h}\right) \mathrm{Pt} / \mathrm{CuClP}$ catalyst. Conversion vs. time plots and reaction conditions are given in (a); Figure SI-1 and (b); Figure SI-2

A kinetic study was performed for the aerobic oxidation of benzyl alcohol by analysis of the conversion rates at different reaction temperatures. The reaction profile of the Pt catalyst was zero-order with respect to the conversion of benzyl alcohol, showing little dependence of the substrate concentration on the rate of reaction (Figure SI-4). Furthermore, the kinetic data was used to construct an Arrhenius plot (Figure 1a.) to calculate the activation energy for this reaction at $72.4 \mathrm{~kJ} / \mathrm{mol}$. Interestingly, it was noted in our earlier work ${ }^{[10]}$ that different reaction rates and selectivity profiles were observed for equivalent $\mathrm{Au}$ andbo however, be due to the differing extents of extrusion between each material which is now thought to be a consequence of the activation temperatures employed.

Investigation into the kinetics of the TBHP oxidation of benzyl alcohol using the same calcined Pt/CuCIP (Figure 1b.), revealed an activation energy of $23.6 \mathrm{~kJ} / \mathrm{mol}$ under identical conditions and concentrations employed for the aerobic oxidation. This is also in agreement with analogous supported NP materials for peroxide oxidation of benzyl alcohol at $38^{[11]}$

35 and $20^{[12]} \mathrm{kJ} / \mathrm{mol}$, whilst surpassing the values obtained for transition-metal catalysts based on Mo and $\mathrm{W}$ at 84 and 96 $\mathrm{kJ} / \mathrm{mol}$ respectively. ${ }^{[13]}$ The lower activation energy of the peroxide based oxidation is not surprising; given the lower BDE of TBHP juxtaposed with $\mathrm{O}_{2}$, and as reflected, in the activity of

40 the catalyst at temperatures lower than $100{ }^{\circ} \mathrm{C}$. With blank reactions not yielding appreciable conversions (Table SI-1), it is clear that the $\mathrm{Pt} / \mathrm{CuCIP}$ catalyst is able to effectively activate both TBHP and $\mathrm{O}_{2}$ as oxidants.

It is interesting to note the deviation from zero-order 45 kinetics, as observed for the $\mathrm{O}_{2}$ system, after low levels of conversion for the TBHP oxidation. The rate of benzyl alcohol oxidation with TBHP reduces over time and thus indicates a dependence on the concentrations of the benzyl alcohol and/or TBHP in the reaction (Figure SI-5). In contrast, the selectivity of 50 the TBHP oxidation is maintained at $>99 \%$ throughout the course of the reaction, whereas benzoic acid is observed, as a significant by-product, in the aerobic oxidation (Figure SI-4). The higher temperature and pressure required for the $\mathrm{O}_{2}$ oxidation could be responsible for the formation of the benzoic acid over55 oxidation product.

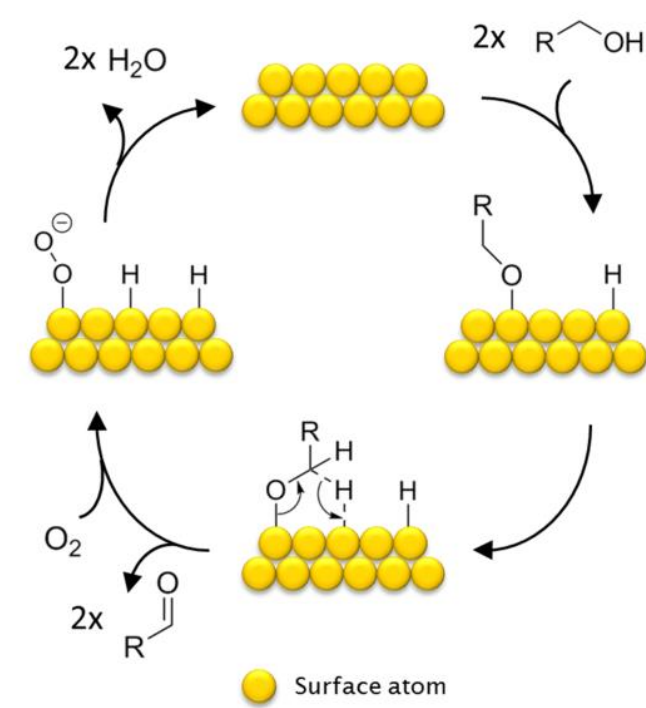

Figure 2. Mechanism for aerobic oxidation of an alcohol to an aldehyde on a metallic NP surface in organic media

For Pt NPs, it is generally accepted that the mechanism of action varies between aqueous and organic media, ${ }^{[14]}$ whereby water facilitates radical-type processes ${ }^{[15]}$ and organic media 
promotes heterolytic mechanisms, as with Au NP systems. Through extensive studies on Au NPs, it has been determinect5 that the adsorption of $\mathrm{O}_{2}$ or peroxides can form activated surface-adsorbed superoxide or surface-peroxide species that

5 can facilitate the dehydrogenation process (Figure 2.). ${ }^{[16]}$ The subsequent adsorption of the alcohol to form an adsorbed surface-alcoholate species then occurs. Abstraction of the $\beta 50$ hydride to the surface of the metal generates the desorbed aldehyde species, with the surface hydrides reacting with the

10 activated surface peroxo-species to form water and regenerate sites for adsorption and further catalytic cycles. ${ }^{[17]}$ It is likely that similar mechanisms operate also for Pt NP systems in organiक5 solvents, including these Pt/CuCIP catalysts.

Before probing the catalytic properties of these materials

15 an ideal candidate was to be selected and thus, a range of catalysts activated under different calcination temperatures (200 - $600{ }^{\circ} \mathrm{C}$ ) were subjected to $\mathrm{X}$-ray absorption fine structureso (XAFS) analysis and herein contrasted, in order to determine whether the extent of extrusion is indeed, a function of

20 temperature. The first shell extended X-ray absorption fine structure (EXAFS) fitting parameters are shown in Table SI-2, along with the magnitude and imaginary components of the $k^{3}$ weighted Fourier transform data and their corresponding fits in Figure SI-5. The EXAFS data shows a mild increase in Pt-Pt 25 coordination numbers $(0.8-1.2)$ and a respective decrease in $\mathrm{Pt}-\mathrm{Cl}$ coordination $(4.5$ - 3.7), suggesting a minor relation between the extent of NP formation and the calcination temperature. Despite the percentage errors, particularly with the lower coordination numbers being larger than desired, the trend

30 is supported by catalytic comparisons with TBHP. The percentage conversions shown in Table 1 display a significant and progressive increase with catalyst calcination temperatures, which provide a clear indication that the activation temperature is directly related to NP formation (via extrusion), and that this

35 has a direct influence on the catalytic activity of these materials.

Table 1. Conversions and product distributions of $\mathrm{Pt} / \mathrm{CuClP}$ catalysts 70 activated under increasing calcination temperature

\begin{tabular}{|c|c|c|c|c|}
\hline $\begin{array}{l}\text { Calcination } \\
\text { Temperature }\end{array}$ & Conversion & $\begin{array}{l}\text { Benzaldehyde } \\
(\%)\end{array}$ & $\begin{array}{l}\text { Benzoic } \\
\text { Acid (\%) }\end{array}$ & $\begin{array}{l}\text { Benzyl } \\
\text { Benzoate (\%) }\end{array}$ \\
\hline $200{ }^{\circ} \mathrm{C}$ & 14.9 & $>99.0$ & 0.0 & 0.0 \\
\hline $400^{\circ} \mathrm{C}$ & 21.8 & $>99.0$ & 0.0 & 0.0 \\
\hline $500{ }^{\circ} \mathrm{C}$ & 38.6 & 97.8 & 2.2 & 0.0 \\
\hline $600^{\circ} \mathrm{C}$ & 86.9 & 65.4 & 34.3 & 0.3 \\
\hline
\end{tabular}

Reaction conditions: $65^{\circ} \mathrm{C}, 6 \mathrm{~h}$, benzyl alcohol $(27.7 \mathrm{mmol})$, substrate to oxidant $(\mathrm{TBHP})$ mole ratio $=1.00: 1.15$, diethylene glycol dimethyl ether $(11.2 \mathrm{mmol})$ and catalyst, calcined for $2 \mathrm{~h}(50 \mathrm{mg})$

Nevertheless, it has been observed that when the 85 calcination temperature exceeds $500{ }^{\circ} \mathrm{C}$, the selectivity of the catalyst drastically diminishes. In addition, it was previously noted ${ }^{[18]}$ that these materials can become victim to thermal degradation at temperatures in excess of $600{ }^{\circ} \mathrm{C}$, and indeed, inconsistencies within the powder X-ray diffraction patterns.90 (PXRD) of these materials are observed at such elevated temperatures (Figure SI-6). Thus, as a result of these observations, all kinetic work conducted herein with the $\mathrm{Pt} / \mathrm{CuCIP}$ catalysts were subject to activation via calcination at $500{ }^{\circ} \mathrm{C}$, and with optimized oxidant to substrate ratios for maximizing the reaction selectivity towards benzaldehyde.

With the EXAFS fitting parameters presented in Table 2. taken into consideration, the $\mathrm{Pt}-\mathrm{Cl}$ and $\mathrm{Pt}-\mathrm{Pt}$ coordination numbers clearly show that only a fraction of the chlorometallate anions have been extruded to form metallic NPs on the surface of the materials, which is consistent with our earlier microscopy studies. ${ }^{[10]}$ As the rate of reaction is correlated with available active sites on the NP surface and the activation energy directly associated with the rates of reaction; it is noteworthy that the activation energies observed in our (partially) activated catalysts compete with those reported in the literature with analogous materials. ${ }^{[11,12]}$ Therefore, with an established method for complete extrusion, it should be possible to significantly improve on these values. Further analysis of activation parameters on structural properties and extent of extrusion is currently ongoing.

Table 2. EXAFS fitting parameters for the Pt/CuCIP material calcined for 2 $h$ at $500^{\circ} \mathrm{C}$

\begin{tabular}{llllll}
\hline Abs Sc & $N$ & $R / \AA$ & $2 \sigma^{2} / \AA^{2}$ & $E_{f} / e V$ & $R_{\text {factor }}$ \\
\hline $\mathrm{Pt}-\mathrm{Cl}$ & $4.4(2)$ & $2.320(6)$ & $0.0026(4)$ & $9(1)$ & 0.013 \\
$\mathrm{Pt}-\mathrm{Pt}$ & $1.4(5)$ & $2.78(2)$ & $0.004(2)$ & & \\
\hline
\end{tabular}

Fitting parameters: $\mathrm{S}_{0}{ }^{2}=0.91$ as deduced by $\mathrm{Pt}$ foil standard; fit range $3<k<12.5,1<R<3$; \# of independent points $=12$

In summary, a combination of spectroscopic and catalytic approaches have revealed that activation conditions play a crucial role in controlling the morphology, size and local structural environment of $\mathrm{Pt}$ nanoparticle catalysts, which are generated by a one-step extrusion process. Spectroscopic and kinetic analysis further illustrate that the presence of well-defined and isolated nanoparticles is fundamental to activating molecular oxygen, for the aerobic oxidation of benzylic alcohols, and the ensuing structure-property correlations pave the way for the predictive design of solid catalysts. Comparison of activation energies showed a higher value for aerobic oxidation at 72.4 $\mathrm{kJ} / \mathrm{mol}$, compared with $23.6 \mathrm{~kJ} / \mathrm{mol}$ for the TBHP oxidation. The aerobic oxidation sustained high rates of conversion with zeroorder kinetics and thus negligible influence of substrate concentrations on reaction rates. On the other hand, the reaction 80 had a reduced selectivity, with benzoic acid formed as a significant by-product, due to the high temperature and pressures required. Oxidation with TBHP maintained a high level of selectivity with negligible quantities of by-products formed. This was, however, limited by substrate concentration effects that resulted in heavily reduced rates of reaction after 4-5 hours. The Pt/CuCIP NP catalyst was successful in activating both of these green alternative oxidants, bestowing unique advantages to each process, thereby affording considerable scope for the further exploitation of these catalysts and design strategy. Given the above, the oxidant can be opportunistically selected depending on whether selectivity for the aldehyde or acid is 
required, notwithstanding the requirement to maintain high reaction rates.

This general approach in evaluating oxidation potentials of nanoparticle-based materials, through the integration of detailed ${ }^{45}$

5 structural characterization and analysis of chemical environments, allows for precise molecular engineering of heterogeneous single-site nanocatalysts with applications in कुo wide-array of organic processes. As hybrid nanomaterials have also been utilized elsewhere in hydrogenation and C-C coupling

10 reactions, ${ }^{[19]}$ as well as for sensors, ${ }^{[20]}$ therapeutic agents and other bio-related applications, ${ }^{[21]}$ it is possible to envisage simila 55 approaches to achieve fundamental understanding of materials for the development of new technologies.

\section{Acknowledgements}

$15 \mathrm{CSH}$ thanks the University of Southampton for a VC scholarship. ${ }^{65}$ We thank Diamond Light Source for access to beamline B18 (SP8071-6) that facilitated and contributed to the results presented here. The UK Catalysis Hub is kindly thanked foro resources and support provided via our membership of the UK

20 Catalysis Hub Consortium and funded by EPSRC (portfolio grants EP/K014706/1, EP/K014668/1, EP/K014854/1 and $\mathrm{EP} / \mathrm{K} 014714 / 1)$

Keywords: Selective Oxidation - Platinum Nanoparticles • Peroxide Oxidation • EXAFS• Molecular Oxygen Activation

[1] K.-G. Fahlbusch, F.-J. Hammerschmidt, J. Panten, W. Pickenhagen, D. Schatkowski, K. Bauer, D. Garbe, H. Surburg, in Ullmann's Encyclopedia of Industrial Chemistry, Vol. 15, 7th ed., Wiley-VCH Verlag GmbH \& Co. KGaA, 2003, pp. 73-198.

30 [2] (a) F. Brühne, E. Wright, in Ullmann's Encyclopedia of Industrial Chemistry, Vol. 5, 7th ed., Wiley-VCH Verlag GmbH \& Co. KGaA, 2011, pp. 223-235; (b) J. L. Opgrande, E. Brown, M. Hesser, J. Andrews, in 90 Kirk-Othmer Encyclopedia of Chemical Technology, John Wiley \& Sons, Inc., 2003.

35 [3] (a) G. Franz, R. A. Sheldon, in Ullmann's Encyclopedia of Industrial Chemistry, Vol. 25, 7th ed., Wiley-VCH Verlag GmbH \& Co. KGaA, 2000, pp. 543-600; (b) I. W. C. E. Arends, R. A. Sheldon, in Modern Oxidation Methods (Ed.: J.-E. Bäckvall), Wiley-VCH Verlag GmbH \& Co. KGaA, Weinheim, 2004, pp. 83-118.

40 [4] R. A. Sheldon, Chem. Soc. Rev. 2012, 41, 1437-1451.
[5] E. P. Clifford, P. G. Wenthold, R. Gareyev, W. C. Lineberger, C. H. DePuy, V. M. Bierbaum, G. B. Ellison, The Journal of Chemical Physics 1998, 109, 10293-10310.

[6] V. I. Vedeneyev, Bond Energies, Ionization Potentials and Electron Affinities, Hodder \& Stoughton Educational, London, 1966

[7] (a) Y.-F. Huang, M. Zhang, L.-B. Zhao, J.-M. Feng, D.-Y. Wu, B. Ren Z.-Q. Tian, Angew. Chem., Int. Ed. 2014, 53, 2353-2357; (b) J. Gong, C. B. Mullins, Acc. Chem. Res. 2009, 42, 1063-1073; (c) D. Widmann, R. J. Behm, Acc. Chem. Res. 2014, 47, 740-749; (d) D. I. Enache, J. K. Edwards, P. Landon, B. Solsona-Espriu, A. F. Carley, A. A. Herzing, M. Watanabe, C. J. Kiely, D. W. Knight, G. J. Hutchings, Science 2006, 311, 362-365.

[8] (a) A. Quintanilla, S. García-Rodríguez, C. M. Domínguez, S. Blasco, J. A. Casas, J. J. Rodriguez, Appl. Catal., B 2012, 111-112, 81-89; (b) J. Ni, W.-J. Yu, L. He, H. Sun, Y. Cao, H.-Y. He, K.-N. Fan, Green Chem 2009, 11, 756-759; (c) V. Peneau, Q. He, G. Shaw, S. A. Kondrat, T. E. Davies, P. Miedziak, M. Forde, N. Dimitratos, C. J. Kiely, G. J. Hutchings, Phys. Chem. Chem. Phys. 2013, 15, 10636-10644.

[9] (a) Y. T. Lai, T. C. Chen, Y. K. Lan, B. S. Chen, J. H. You, C. M. Yang, N. C. Lai, J. H. Wu, C. S. Chen, ACS Catal. 2014, 4, 3824-3836; (b) L. Kesavan, R. Tiruvalam, M. H. A. Rahim, M. I. bin Saiman, D. I. Enache, R. L. Jenkins, N. Dimitratos, J. A. Lopez-Sanchez, S. H. Taylor, D. W. Knight, C. J. Kiely, G. J. Hutchings, Science 2011, 331, 195-199; (c) M. I. bin Saiman, G. L. Brett, R. Tiruvalam, M. M. Forde, K. Sharples, A. Thetford, R. L. Jenkins, N. Dimitratos, J. A. Lopez-Sanchez, D. M. Murphy, D. Bethell, D. J. Willock, S. H. Taylor, D. W. Knight, C. J. Kiely, G. J. Hutchings, Angew. Chem., Int. Ed. 2012, 51, 5981-5985; (d) S. Ghosh, S. S. Acharyya, D. Tripathi, R. Bal, J. Mater. Chem. A 2014, 2, 15726-15733.

[10] C. S. Hinde, S. Van Aswegen, G. Collins, J. D. Holmes, T. S. A. Hor, R Raja, Dalton Trans. 2013, 42, 12600-12605.

[11] G. Zhan, Y. Hong, F. Lu, A.-R. Ibrahim, M. Du, D. Sun, J. Huang, Q. Li, J. Li, J. Mol. Catal. A: Chem. 2013, 366, 215-221.

[12] A. Mehri, H. Kochkar, G. Berhault, D. F. Cómbita Merchán, T. Blasco, Mater. Chem. Phys. 2015, 149-150, 59-68.

[13] M. P. Chaudhari, S. B. Sawant, Chem. Eng. J. 2005, 106, 111-118.

[14] N. Dimitratos, A. Villa, D. Wang, F. Porta, D. Su, L. Prati, J. Catal. 2006, 244, 113-121.

[15] (a) Y. Hong, X. Yan, X. Liao, R. Li, S. Xu, L. Xiao, J. Fan, Chem. Commun. 2014, 50, 9679-9682; (b) T. Wang, H. Shou, Y. Kou, H. Liu, Green Chem. 2009, 11, 562-568.

[16] A. Abad, A. Corma, H. García, Chem. Eur. J. 2008, 14, 212-222.

[17] (a) H. Tsunoyama, H. Sakurai, Y. Negishi, T. Tsukuda, J. Am. Chem. Soc. 2005, 127, 9374-9375; (b) P. Fristrup, L. Johansen, C. Christensen, Catal. Lett. 2008, 120, 184-190.

[18] E. R. Williams, R. M. Leithall, R. Raja, M. T. Weller, Chem. Commun 2013, 49, 249-251.

[19] (a) G. Collins, M. Schmidt, C. O'Dwyer, J. D. Holmes, G. P. McGlacken, Angew. Chem., Int. Ed. 2014, 53, 4142-4145; (b) Z. Wang, K.-D. Kim, C. Zhou, M. Chen, N. Maeda, Z. Liu, J. Shi, A. Baiker, M. Hunger, J. Huang, Catal. Sci. Technol. 2015, 5, 2788-2797.

[20] J. Xie, Y. Zheng, J. Y. Ying, Chem. Commun. 2010, 46, 961-963.

[21] B. H. Kim, M. J. Hackett, J. Park, T. Hyeon, Chem. Mater. 2013, 26, 5971. 
Entry for the Table of Contents (Please choose one layout)

Layout 1:

\section{COMMUNICATION}

A versatile design strategy for the in situ generation of well-defined platinum nanoparticles, which are heterogenized by anion extrusion within porous framework architectures, affords dextrous control for tuning the local structural environment of the active site, in enabling industrially-significant, sustainable catalytic oxidations.

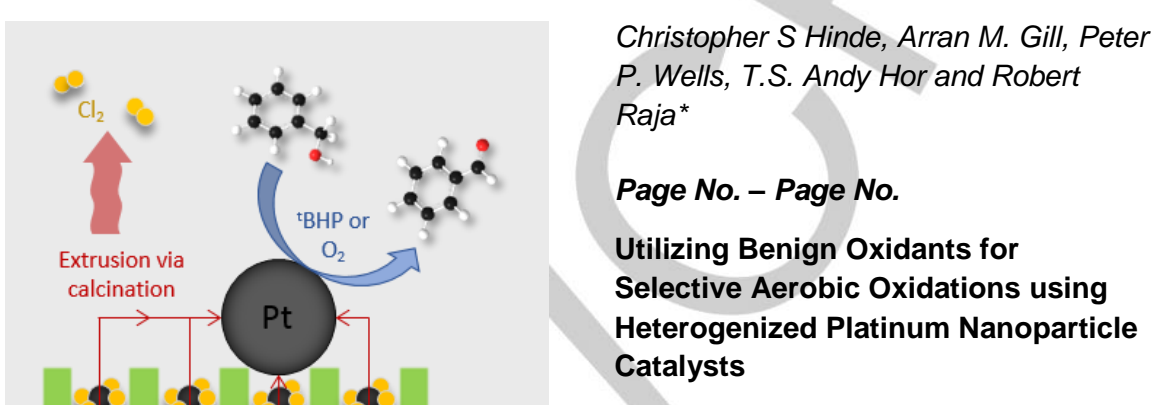




\section{Contents}

1. Experimental section

2. Kinetic plots for aerobic oxidation of benzyl alcohol

3. Kinetic plots for TBHP oxidation of benzyl alcohol

4. Concentration profiles for aerobic oxidation of benzyl alcohol

5. Concentration profiles for TBHP oxidation of benzyl alcohol

6. EXAFS data \& fits

7. EXAFS fitting parameters

8. Powder X-ray diffraction analysis

9. Bibliography 


\section{Experimental section}

Synthesis of 7 wt \% Pt/CuCIP: Copper(II) fluoride (1.150 mmol), 85 wt.\% orthophosphoric acid (2.922 mmol), 50 wt. $\% \mathrm{RbOH}(2.037 \mathrm{mmol}), \mathrm{RbCl}(2.316 \mathrm{mmol})$ and $\mathrm{K}_{2} \mathrm{PtCl}_{4}(0.124 \mathrm{mmol})$ were mixed in the PTFE liner of a custom-made $23 \mathrm{~cm}^{3}$ hydrothermal vessel. The vessel was sealed and heated to $448 \mathrm{~K}$ for 2 days. Products formed as brilliant green cuboid crystals for the Pt copper chlorophosphate material. Materials were further activated by calcination (air, $2 \mathrm{~h}$ ) at designated temperatures to generate the active NP catalysts. After calcination, the materials appeared a darker khaki-green.

Catalytic reactions with $\mathrm{O}_{2}$ : High-pressure reactions were carried out in a $75 \mathrm{~cm}^{3}$ PTFE lined, stainless-steel Parr batch reactor. The reactor was charged with benzyl alcohol $(9.247 \mathrm{mmol})$, diethylene glycol dimethyl ether $(6.335 \mathrm{mmol})$ as an internal standard, $t$-butanol $(30 \mathrm{~mL})$ as a solvent and catalyst $(50 \mathrm{mg})$. The reactor was pressurized with $\approx 20$ bar of dry air (yielding an oxidant to substrate molar ratio of 1:0.85), stirred and heated for the required amount of time. Small aliquots of the reaction mixture were taken carefully periodically for GC analysis. Samples were analyzed by GC (PerkinElmer, Clarus 480) using an Elite-5 column equipped with a flame ionization detector (FID). Products were identified against authenticated standards and quantified by calibration to obtain response factors (RF) against the known internal standard.

Catalytic reactions with TBHP: A standard reflux setup was charged with benzyl alcohol (4.624 mmol), diethylene glycol dimethyl ether $(2.981 \mathrm{mmol})$ as an internal standard, $t$-butanol $(15 \mathrm{~mL})$ as a solvent and catalyst (25 mg). TBHP (11.0 mmol in decane) was added lastly yielding a substrate to oxidant molar ratio of 1:0.85. The reaction was stirred and heated for the required amount of time. Small aliquots of the reaction mixture were taken carefully periodically for GC analysis, as above.

XAFS: Pt $\mathrm{L}_{3}$-edge XAFS measurements were carried out on the B18 beamline at the Diamond Light Source, Didcot, UK. Measurements were performed using a QEXAFS set-up with a fast-scanning Si (111) double crystal monochromator. The normal time resolution of the spectra reported herein was $1 \mathrm{~min} / \mathrm{spectrum}\left(\mathrm{k}_{\max }=16\right)$, on average six scans were acquired to improve the signal to noise level of the data. All samples were diluted with cellulose and pressed into pellets to optimize the effective edge-step of the XAFS data and measured in transmission mode using ion chamber detectors. All transmission XAFS spectra were acquired concurrently with the appropriate reference foil placed between $I_{t}$ and $I_{\text {ref. }}$ XAS data processing and EXAFS analysis were performed using IFEFFIT with the Horae package (Athena and Artemis). ${ }^{[1,2]}$ The amplitude reduction factor, $\mathrm{s}_{\circ}{ }^{2}$, was derived from EXAFS data analysis of known compounds, and used as a fixed input parameter.

PXRD: Data were collected on a Bruker D2 Phaser in theta-theta geometry using $\mathrm{Cu}(\mathrm{K} \alpha 1 / \mathrm{K} \alpha 2)$ radiation and a $\mathrm{Ni} \mathrm{K} \beta$ filter (detector side). Additional beam optics and settings: primary and secondary axial Soller slits $\left(2.5^{\circ}\right)$, fixed $0.6 \mathrm{~mm}$ divergence slit, $1 \mathrm{~mm}$ anti-scatter-screen, Detector: 1D LYNXEYE with a $5^{\circ}$ window, Generator: $30 \mathrm{kV}$, $10 \mathrm{~mA}$. 


\section{Kinetic plots for aerobic oxidation of benzyl alcohol}

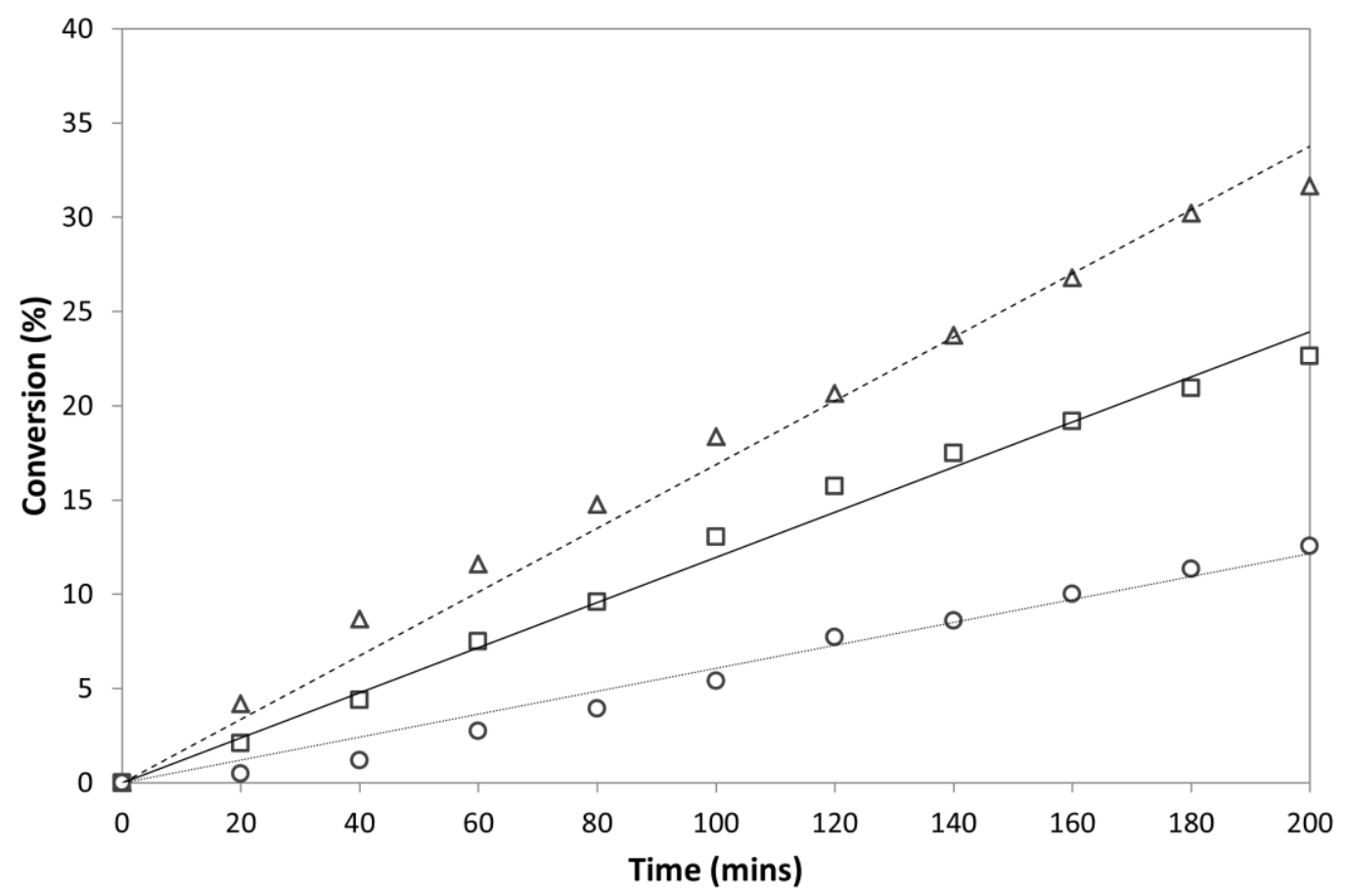

Figure SI-1 - Kinetic plot showing conversion of benzyl alcohol by aerobic oxidation with the calcined $\left(500{ }^{\circ} \mathrm{C}, 2 \mathrm{~h}\right) \mathrm{Pt} / \mathrm{CuClP}$ at $110^{\circ} \mathrm{C}$ (circles), $120^{\circ} \mathrm{C}$ (squares) and $130^{\circ} \mathrm{C}$ (triangles). Reaction conditions: benzyl alcohol $(9.247 \mathrm{mmol})$, catalyst (50 $\mathrm{mg})$, diglyme as internal standard $(6.335 \mathrm{mmol}), t$-butanol $(30 \mathrm{~mL})$, air $(20$ bar), oxidant to substrate molar ratio of 1:0.85

\section{Kinetic Plots for TBHP oxidation of benzyl alcohol}

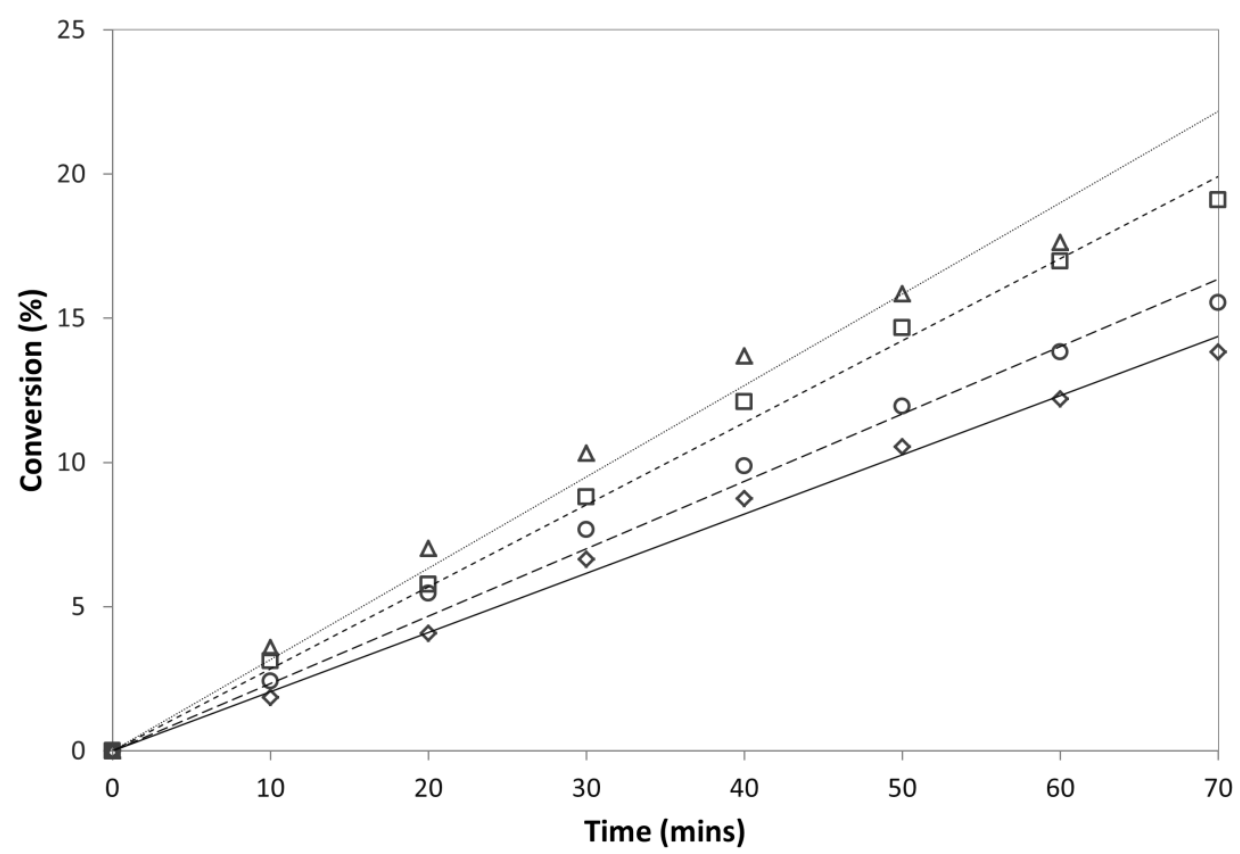

Figure SI-2 - Kinetic plot showing conversion of benzyl alcohol by TBHP oxidation with the calcined $\left(500^{\circ} \mathrm{C}, 2 \mathrm{~h}\right) \mathrm{Pt} / \mathrm{CuClP}$ at $87^{\circ} \mathrm{C}$ (diamonds) $95^{\circ} \mathrm{C}$ (circles), $100{ }^{\circ} \mathrm{C}$ (squares) and $110^{\circ} \mathrm{C}$ (triangles). Reaction conditions: benzyl alcohol (4.624 mmol), catalyst $(25 \mathrm{mg})$, diglyme as internal standard $(2.981 \mathrm{mmol}), t$-butanol $(15 \mathrm{~mL})$, TBHP $(11.0 \mathrm{mmol}$ in decane), oxidant to substrate molar ratio of 1:0.85 


\section{Concentration profiles for aerobic oxidation of benzyl alcohol}

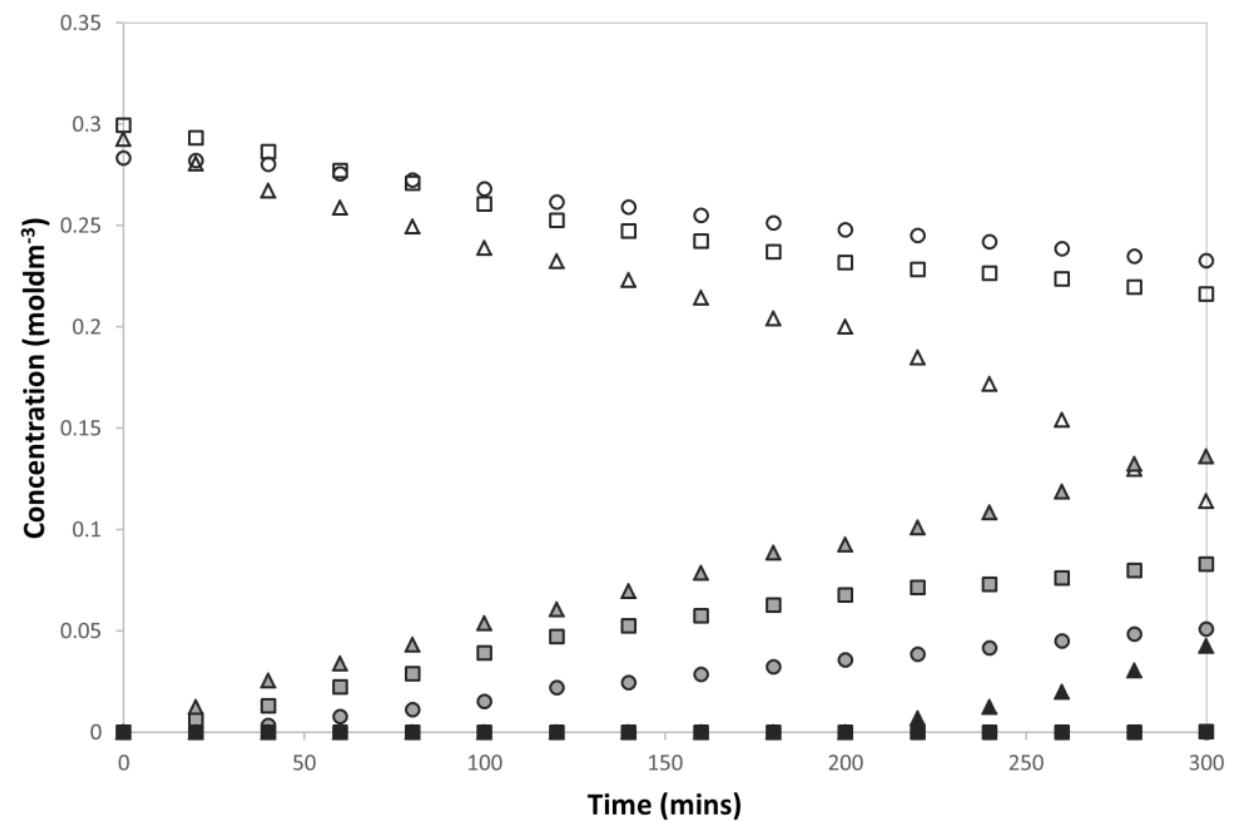

Figure SI-3 - Plot showing the change in benzyl alcohol (white fill), benzaldehyde (grey fill) and benzoic acid (black fill) concentration with time in the aerobic oxidation of benzyl alcohol with the calcined $\left(500{ }^{\circ} \mathrm{C}, 2 \mathrm{~h}\right) \mathrm{Pt} / \mathrm{CuClP}$ at $110^{\circ} \mathrm{C}$ (circles), $120^{\circ} \mathrm{C}$ (squares) and $130^{\circ} \mathrm{C}$ (triangles). Reaction conditions: benzyl alcohol (9.247 mmol), catalyst (50 mg), diglyme as internal standard $(6.335 \mathrm{mmol}), t$-butanol $(30 \mathrm{~mL})$, air (20 bar), oxidant to substrate molar ratio of 1:0.85

\section{Concentration profiles for TBHP oxidation of benzyl alcohol}

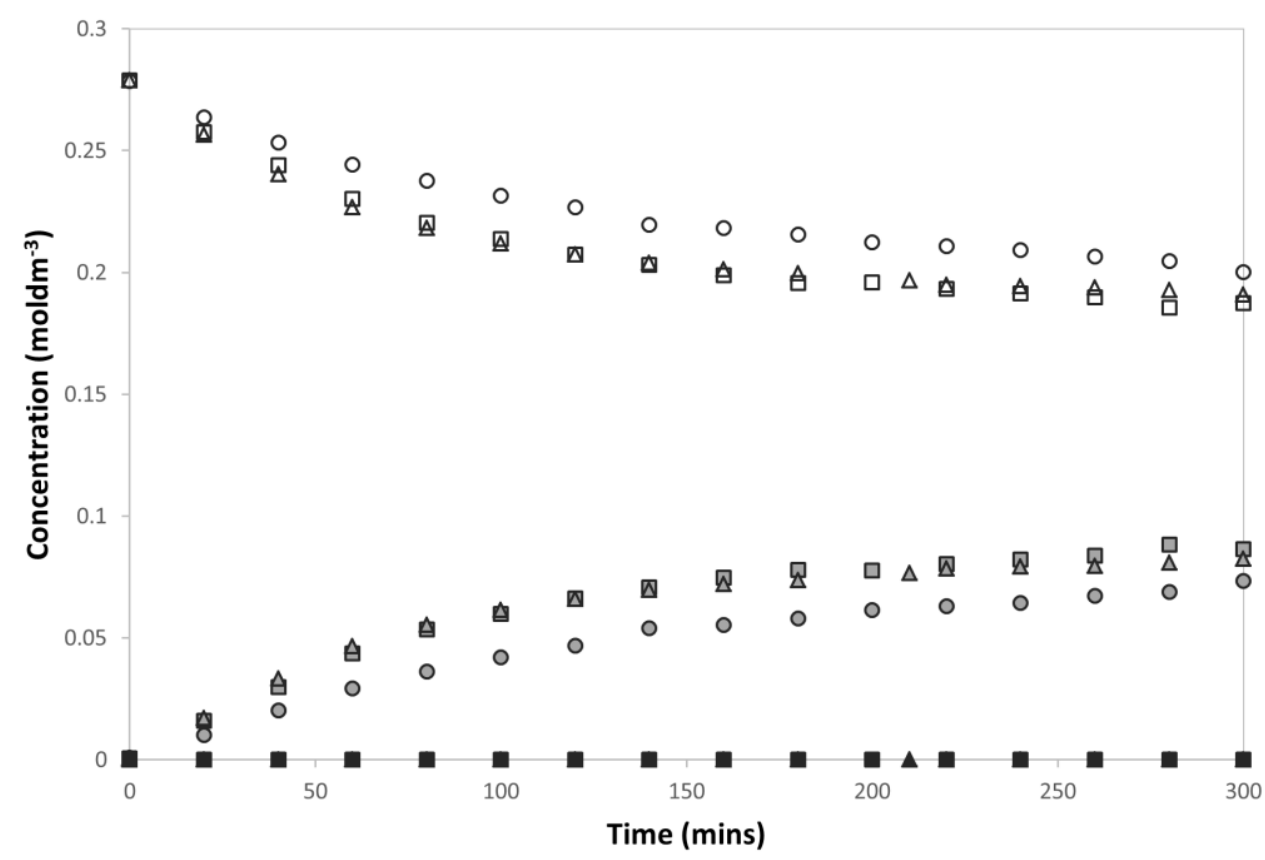

Figure SI-4 - Plot showing the change in benzyl alcohol (white fill), benzaldehyde (grey fill) and benzoic acid (black fill) concentration with time in the TBHP oxidation of benzyl alcohol with the calcined $\left(500{ }^{\circ} \mathrm{C}, 2 \mathrm{~h}\right) \mathrm{Pt} / \mathrm{CuClP}$ at $86{ }^{\circ} \mathrm{C}$ (circles), $100{ }^{\circ} \mathrm{C}$ (squares) and $110^{\circ} \mathrm{C}$ (triangles). Reaction conditions: benzyl alcohol (4.624 mmol), catalyst ( $25 \mathrm{mg}$ ), diglyme as internal standard $(2.981 \mathrm{mmol}), t$-butanol $(15 \mathrm{~mL})$, TBHP $(11.0 \mathrm{mmol}$ in decane), oxidant to substrate molar ratio of 1:0.85 
6. Additional catalysis data

\begin{tabular}{cccccc}
\hline Oxidant & $\begin{array}{c}\text { Temperature } \\
/{ }^{\circ} \mathrm{C}\end{array}$ & $\begin{array}{c}\text { Time / } \\
\text { min }\end{array}$ & $\begin{array}{c}\text { Conversion } \\
/ \%\end{array}$ & $\begin{array}{c}\text { Benzaldehyde } \\
\text { Selectivity / \% }\end{array}$ & $\begin{array}{c}\text { Benzoic Acid } \\
\text { Selectivity / \% }\end{array}$ \\
\hline \hline Air $^{[a]}$ & 130 & 300 & 8 & $>99$ & 0 \\
$\mathrm{TBHP}^{[b]}$ & 110 & 300 & 6 & $>99$ & 0
\end{tabular}

Table SI-1 - Full blank reaction results with corresponding conversions and selectivities at the quoted temperature and reaction time. Reaction conditions [a]: benzyl alcohol ( $9.247 \mathrm{mmol})$, diglyme as internal standard (6.335 $\mathrm{mmol}), t$-butanol $(30 \mathrm{~mL})$, air (20 bar), oxidant to substrate molar ratio of 1:0.85. Reaction conditions [b]: benzyl alcohol (4.624 mmol), diglyme as internal standard (2.981 mmol), $t$-butanol $(15 \mathrm{~mL})$, TBHP (11.0 mmol in decane), oxidant to substrate molar ratio of 1:0.85

\section{EXAFS data \& fits}

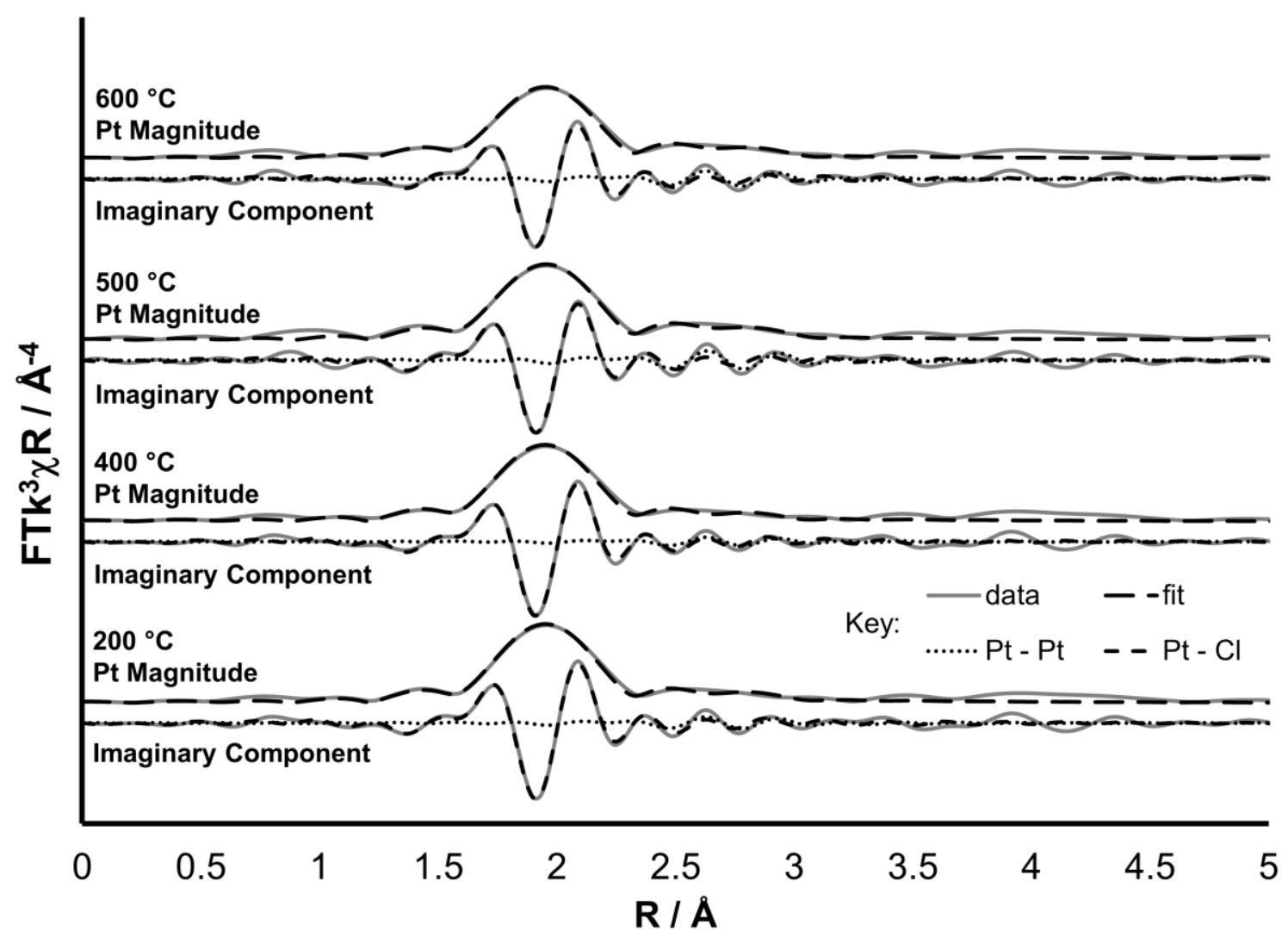

Figure SI-5 - Magnitude and imaginary component of the $\mathrm{k}^{3}$ weighted Fourier transform for the EXAFS data of the Pt/CuCIP materials calcined $(2 \mathrm{~h})$ under increasing activation temperature, ascending up the plot. Associated scattering paths are included for the imaginary component 


\section{EXAFS fitting parameters}

\begin{tabular}{ccccccc}
\hline Sample & Abs Sc & $\mathbf{N}$ & $\mathbf{R} / \AA$ & $\mathbf{2 \sigma}^{2} / \AA^{2}$ & $\mathbf{E}_{\mathbf{f}} / \mathbf{e V}$ & $\mathbf{R}_{\text {factor }}$ \\
\hline \hline $\mathrm{Pt} / \mathrm{CuClP}$ & $\mathrm{Pt}-\mathrm{Cl}$ & $4.5(2)$ & $2.320(5)$ & $0.0024(3)$ & $8.8(9)$ & 0.010 \\
$200{ }^{\circ} \mathrm{C}$ & $\mathrm{Pt}-\mathrm{Pt}$ & $0.8(5)$ & $2.77(3)$ & $0.004(2)$ & & \\
& & & & & & \\
$\mathrm{Pt} / \mathrm{CuClP}$ & $\mathrm{Pt}-\mathrm{Cl}$ & $5.0(2)$ & $2.319(5)$ & $0.0026(3)$ & $8.8(9)$ & 0.012 \\
$400{ }^{\circ} \mathrm{C}$ & $\mathrm{Pt}-\mathrm{Pt}$ & $0.8(8)$ & $2.78(4)$ & $0.004(4)$ & & \\
& & & & & & \\
$\mathrm{Pt} / \mathrm{CuClP}$ & $\mathrm{Pt}-\mathrm{Cl}$ & $4.4(2)$ & $2.320(6)$ & $0.0026(4)$ & $9(1)$ & 0.013 \\
$500^{\circ} \mathrm{C}$ & $\mathrm{Pt}-\mathrm{Pt}$ & $1.4(5)$ & $2.78(2)$ & $0.004(2)$ & & \\
& & & & & \\
$\mathrm{Pt} / \mathrm{CuClP}$ & $\mathrm{Pt}-\mathrm{Cl}$ & $3.7(2)$ & $2.317(5)$ & $0.0025(3)$ & $9.2(9)$ & 0.011 \\
$600{ }^{\circ} \mathrm{C}$ & $\mathrm{Pt}-\mathrm{Pt}$ & $1.2(5)$ & $2.78(2)$ & $0.005(2)$ & & \\
\hline
\end{tabular}

Table SI-2 - EXAFS fitting parameters of the Pt/CuCIP materials calcined $(2 \mathrm{~h})$ under increasing activation temperature. $\mathrm{S}_{0}{ }^{2}$ $=0.91$ as deduced by Pt foil standard; fit range $3<k<12.5,1<R<3$; \# of independent points $=12$

\section{Powder X-ray diffraction analysis}

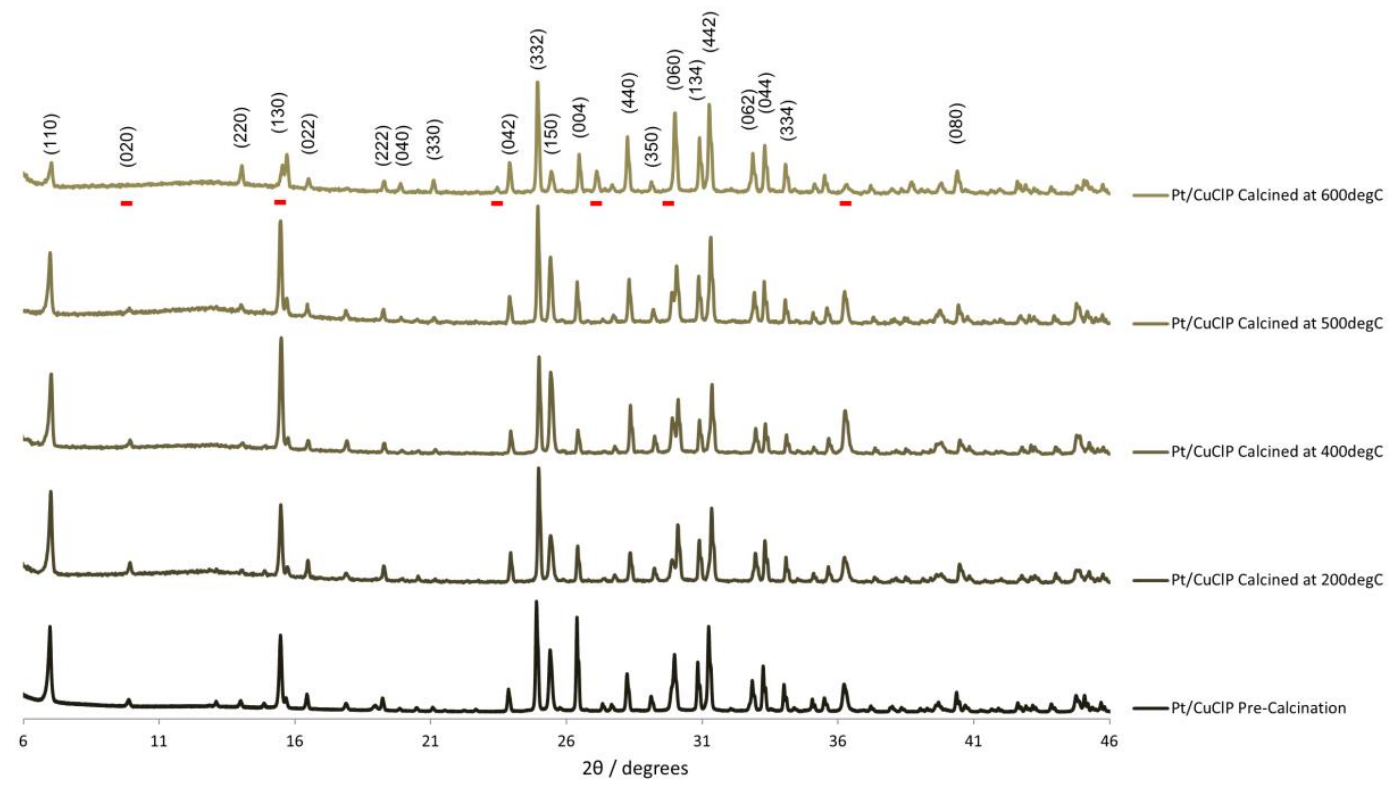

Figure SI-6 - Indexed PXRD patterns for the Pt/CuClP under increasing calcination temperature. Data shown of the uncalcined sample through $200,400,500$ and $600{ }^{\circ} \mathrm{C}$ up the plot (all materials were calcined for $2 \mathrm{~h}$ ). Changes in the PXRD pattern are observed when the material is calcined at $600{ }^{\circ} \mathrm{C}$ which have been highlighted with red markers

\section{Bibliography}

[1] M. Newville, J. Synchrotron Radiat. 2001, 8, 322-324.

[2] B. Ravel, M. Newville, J. Synchrotron Radiat. 2005, 12, 537-541. 